\title{
Epidemiological Studies on Calve Coccidiosis in Dairy Farms in South Wollo Zone Amhara Region, Ethiopia
}

\section{Getahun Kassa Temesgen*}

Ethiopian Institute of Agricultural Research, Holeta Agricultural Research Center, Ethiopia

\begin{abstract}
A cross-sectional study was conducted from December 2015 up to April 2016 to determine the prevalence of calf Coccidiosis, identify the associated risk factors and to determine the intensity of infection in selected dairy farms from eight woreda of south Wollo zone, Ethiopia. Fecal samples were randomly collected from nine hundred calves belonging to twenty purposively selected dairy farms and were examined for the presence of the oocysts of Eimeria by floatation technique using concentrated sucrose solution. The study revealed that the overall prevalence of coccidiosis was $24.3 \%$. The risk factors considered were age, breed, production system and hygiene status of the dairy farms. The prevalence of Coccidiosis was higher within calves in poor hygiene dairy farms than caves from better hygiene. There was significant difference $(\mathrm{P}<0.05)$ in the prevalence of Coccidiosis between the different age groups with the highest prevalence in age category less than 6 months (31.5\%). There was also significant variation $(\mathrm{P}<0.05)$ between calf breeds. The highest prevalence of Coccidiosis was recorded in calves with diarrheic faeces $(61.5 \%)$ than the other calves with soft and normal fecal consistency $(\mathrm{P}<0.05)$. Appropriate monitoring and control of the disease is advisable in the study farms.
\end{abstract}

Keywords: Calves; Coccidiosis; Dairy farms; South wollo; Ethiopia; Prevalence; Risk factors

\section{Introduction}

Ethiopia, located in Eastern Africa, is predominantly an agricultural nation. Animal production is practiced in all ecological zones of the country [1]. The total population for the country is estimated to be about 53.99 million cattle in which out of this population $9.77 \%$ of the cattle are under 6 month age group and $7.64 \%$ of its total population are between 6 month and 1 year. On the other hand, 98.95 percent of the total cattle in the country are local breeds and the remaining are hybrid and exotic breeds that accounted for about 0.94 percent and 0.11 percent, respectively [2].

Ethiopia's great livestock potential is not properly exploited due to many prevailing socio economic values and attitudes, traditional management methods, limited genetic potential and rampant disease. Gastrointestinal parasite infections are major problem for both smalland large-scale farms in Ethiopia [3]. The most important disease problems in the area in the young calf are pneumonia and diarrhea. The important pathogens associated with calf diarrhea are rotavirus, corona virus, Salmonella species, and protozoan parasites Eimeria and Cryptosporidium species. Coccidiosis is the common health problem particularly in neonatal calf that is responsible for the greatest economic losses in this age group for both dairy and beef calves and acute diarrhea accounts for approximately $75 \%$ of the mortality losses of dairy calves less than 3 weeks age [4].

The most pathogenic and economically important Eimeria species causing coccidiosis in calves were Eimeria bovis and Eimeria zuernii [5]. All calves managed under conventional systems are exposed to coccidia and become infected early in life. Coccidiosis in cattle is particularly a problem of confined animals kept under intensive husbandry practices. Coccidiosis spreads from one animal to another by contact with infected feces and is one of the most alarming problems for calf rearing industry [6].

Coccidiosis results a marked reduction in feed efficiency and weight gain. As the disease progresses, feed and water intake steadily declines, resulting in dehydration. If weight loss and dehydrations are severe enough, calves may die from coccidiosis. Moreover, it results in failure of young stock to gain weight and to grow to their full potential. In many instances, coccidiosis is a silent thief, robbing of performance but never visibly showing most of its symptoms, though the most common of which is bloody diarrhea [7].

Apart from few studies in some parts of the zone, there is no previous detail information on the prevalence of coccidiosis in the country. Although coccidiosis is an important cause of calf morbidity and mortality, very little attention has been given to the disease and losses.

Therefore, taking into account the significance of the parasite as one of the most important causes of economic losses and the scarcity of information in the area the objective of the study was to determine the prevalence of coccidiosis in calves and its surroundings risk factors associated with it. And, to determine the intensity of infection.

\section{Materials and Methods}

\section{Study area}

The present study was conducted in purposively selected twenty dairy farm of the Amhara region south wollo zone Ethiopia. The areas included in the study were, Dessie zone city, Dessie zuriya woreda, Kombolcha Woreda and Kalu woreda.

*Corresponding author: Getahun Kassa Temesgen, Ethiopian Institute of Agricultura Research, Holeta Agricultural Research Center, PO Box 31, Holeta, Ethiopia, Tel: +251933864380; Fax: 0112370377; E-mail: Temesgen.kassa@yahoo.com

Received September 30, 2016; Accepted October 26, 2016; Published October 31, 2016

Citation: Temesgen GK (2016) Epidemiological Studies on Calve Coccidiosis in Dairy Farms in South Wollo Zone Amhara Region, Ethiopia. J Vet Sci Technol 7: 392. doi: $10.4172 / 2157-7579.1000392$

Copyright: @ 2016 Temesgen GK. This is an open-access article distributed under the terms of the Creative Commons Attribution License, which permits unrestricted use, distribution, and reproduction in any medium, provided the original author and source are credited. 


\section{Study farms and animals selection}

From study area, eight districts, sixteen kebeles and twenty dairy farms; six from Kombolcha (230), four from Dessie Zuriya (200), three from Kalu (170) and seven from the zone city Dessie (300) were selected purposely. The farms were known for their potential of calves' population and most farms production system was intensive management system which is the hot spot for coccidiosis. Once dairy farms are identified and sampling frame is established all calves under one year age were sampled randomly

\section{Sample size determination}

Sample size was calculated with an expected prevalence of $68.1 \%$ from the previous research work on prevalence of calf coccidiosis in Addis Ababa [8]. The desired sample size for the study was determined by using the formula described by Ref. [9].

\section{$\mathrm{n}=1.96^{2} \mathrm{Pexp}(1-\mathrm{Pexp}) / \mathrm{d}^{2}$}

Where $\mathrm{n}=$ required sample size, $\mathrm{d}=$ desired absolute precision. Accordingly, 900 sample size was taken to increase precision.

\section{Study design and sampling strategy}

A cross sectional study design was employed from December 2014 to April 2015 to determine the prevalence of coccidiosis in dairy farms and to asses associated risk factors of coccidiosis both in extensive and intensive production system, and in cross and local breed of calves. Information on farm structure and calve management were collected from 20 farms. The owner or manager of each farm was interviewed in the local language during sample collection. Sanitation status was judged as poor, medium (satisfactory) or good based on aspects such as odor, waste drainage, cleanness of floor and animals, barn ventilation and light source and animal stocking based on the objective criteria developed by FAO and IDF. Body Condition estimation (related animal body gain) was another factor recorded during sample collection. Age and sex were also recorded accordingly.

\section{Sample collection and examination}

Faecal sample collection: About $40 \mathrm{~g}$ fresh faecal sample was collected from rectum from each calf using sterile disposable plastic gloves. The samples were placed in a labeled clean plastic container (universal bottle) and were transported to parasitological laboratory of each woreda on the same day of collection and were preserved at $4^{\circ} \mathrm{C}$ refrigerator until processing within 48 hours of arrival. At the time of sampling, the name of the farm (owner), date of sampling, consistency of the faeces (Diarrheic, soft or normal) and the age, sex, breed, address, body condition, and management system were recorded for each calf on a data recording format.

Laboratory examination of fecal samples: Flotation technique, was employed as follow, a $5 \mathrm{~g}$ portion of each of the $900 \mathrm{fecal}$ samples collected from the total of $60 \mathrm{~g}$ was weighed out using a balance and put in a $50 \mathrm{ml}$ beaker. $42 \mathrm{ml}$ of water was added, mixed thoroughly and poured into a $100 \mathrm{ml}$ glass beaker through a strainer. The $50 \mathrm{ml}$ glass beaker was rinsed with $8 \mathrm{ml}$ of water and the total fluid was poured into four $15 \mathrm{ml}$ conical tip centrifuge tubes. After centrifugation at 1,500 rpm for $3 \mathrm{~min}$, the supernatant was decanted and a sugar solution with specific gravity of 1.27 was added to the sediment, until the tube was about half full. The content of each test tube was thoroughly mixed with a wooden applicator stick. With the aid of a conical flux, more sugar solution was added until $13 \mathrm{ml}$ of the tube is filed with the solution. The mixture was again centrifuged in $1500 \mathrm{rpm}$ for 3 minutes. After centrifugation, the tube was filled to the top until a convex meniscus was formed and a glass cover slip was placed on top of the tube and left for 10 minutes. Then, each glass cover slip was briskly lifted up and placed on a clean glass slide, not allowing formation of air bubbles. The entire area under each cover slip was examined under a microscope at 10X magnification [10].

Quantitative fecal examination: This was performed in positive samples to determine the number of oocysts of Eimeria per gram of feces (OPG). The method used for this purpose was the well-known McMaster technique as described by Johannes [11].

\section{Data analysis}

The entire collected raw data were entered into Microsoft Excel spread sheet and coded. Statistical analyses were performed using SPSS, version 20 software packages. Percentage was used to calculate prevalence. Additionally, chi-square was used to measure degree of association between risk factors and prevalence of coccidiosis. In the analysis, a difference was taken as stastically significant at a p-value less than 0.05 and the results were displayed in the form of tables.

\section{Results}

During the study period, fecal specimens taken from a total of 900 calves were thoroughly examined for the presence of different GI parasites using floatation and sedimentation techniques revealed 218 were found positive with an overall prevalence of $24.3 \%$.

Out of the examined 226 male calves 97 were found positive with the respective prevalence of $42.9 \%$ and from 674 female calves 121 were found positive with the prevalence of $18 \%$. Accordingly, the prevalence of coccidiosis in male was higher than female calves (Table 1).

Out of 601 examined calves with age category less than 6 months and from 299 examined with age between 6 and 12 months age category calves, $183(31.5 \%)$ and $35(11.7 \%)$ were found positive, respectively. Accordingly, the highest prevalence was recorded in those calves with age less than 6 months old age (Table 2).

Prevalence result was indicated as $26.5 \%$ and $10.6 \%$ for cross breed and local breed calves respectively from the total of 900 calves. From this result, cross breed calves have higher prevalence than the local ones (Table 3). The overall prevalence of coccidiosis on the basis of production system was determined and it was most prevalent in intensive than in the calves that were reared under extensive one (Table 4).

\begin{tabular}{|c|c|c|c|}
\hline Sex & No examined & No Positives & Prevalence (\%) \\
\hline Female & 674 & 121 & 18 \\
Male & 226 & 97 & 42.9 \\
\hline
\end{tabular}

Table 1: Prevalence of calf Coccidiosis according to sex.

\begin{tabular}{|c|c|c|c|}
\hline Age (months) & No Calves examined & No Positive & Prevalence (\%) \\
\hline$<6$ & 601 & 183 & 31.5 \\
\hline $6-12$ & 299 & 35 & 11.7 \\
\hline
\end{tabular}

Table 2: Prevalence of calf Coccidiosis by age.

\begin{tabular}{|c|c|c|c|}
\hline Bread & No examined & No Positives & Prevalence (\%) \\
\hline Cross & 773 & 204 & 26.5 \\
\hline Local & 127 & 14 & 10.6 \\
\hline
\end{tabular}

Table 3: Prevalence of calf Coccidiosis by breed.

\begin{tabular}{|c|c|c|c|}
\hline Production system & No examined & No Positives & Prevalence (\%) \\
\hline Extensive & 186 & 33 & 17.4 \\
\hline Intensive & 714 & 185 & 26 \\
\hline
\end{tabular}

Table 4: Prevalence of calf coccidiosis by production system. 
From the total sample, 78 calves were diarrheic of which 48 (61.5\%) were infected with the parasite. Hence the disease is most prevalent in diarrheic animals as compared to the animals with other fecal consistency (Tables 5-7). From the total of 900 calves that were examined $15.7 \%, 27.1 \%$ and $30.0 \%$ prevalence were obtained from good, moderate and bad hygiene of the farm, respectively. Accordingly, calves belonging to the farms with bad hygiene showed higher prevalence $(30.0 \%)$ than calves belonging to the farms with relatively better hygiene.

The observation data result shows sex, age, breed, fecal consistency, production system and hygiene status of the farm are potential risk factors, which are associated with coccidiosis at dairy farms. The McMaster technique employed to determine the OPG revealed that minimum, mean and maximum OPG value of $100,479.5$ and 3700

\begin{tabular}{|c|c|c|c|}
\hline Faecal consistency & No examined & $\begin{array}{c}\text { No } \\
\text { Positives }\end{array}$ & Prevalence (\%) \\
\hline Diarrheic & 210 & 128 & 61.5 \\
\hline Soft & 358 & 57 & 15.8 \\
\hline Normal & 332 & 33 & 9.8 \\
\hline
\end{tabular}

Table 5: Prevalence of calf coccidiosis according to faecal consistency.

\begin{tabular}{|c|c|c|c|}
\hline Hygiene of housing & No examined & No Positives & Prevalence (\%) \\
\hline Good & 275 & 43 & 15.7 \\
\hline Moderate & 436 & 118 & 27.1 \\
\hline Bad & 189 & 57 & 30.0 \\
\hline
\end{tabular}

Table 6: Prevalence of calf Coccidiosis according to hygiene of farms. were observed, respectively. There was high correlation between faecal consistency and body condition (related animal body gain) with intensity of the infection (Table 8)

\section{Discussion}

The present study revealed that overall prevalence of calf Coccidiosis was $24.3 \%$ agree with the previous works reported by Ref. [12] with prevalence of $24.9 \%$ in Bahirdar. But lower than reported by Ref. $[8,13]$ with prevalence of $68.1 \%$, and $51.7 \%$ in Addis Ababa and in Jimma respectively. The possible reason for this reduction in prevalence might be variation in the study season of the year. Relatively high humidity and moderate temperature during rainy season favors the survival and sporulation of the oocyst [14]. The present study was conducted during the dry season of the year which was unfavorable for the survival and sporulation of the oocyst. In addition, since the study area was urban and pre-urban, the periodic deworming of the calves might also be another factor for the variation of reports. It was higher than the previous reported by Heidari et al. [15] (8.25\%) in Iran. This variation is most likely attributed due to the differences in agro-ecologic and production of the studied animals in different countries [6].

Analysis of risk factors in the association of disease occurrence has revealed that there was statistically significant difference $(\mathrm{P}<0.05)$ between sex groups (male $40 \%$ and female $19 \%$ ). This finding disagrees with the report of Ref. $[13,16]$. Some study revealed that sex does not have influence on the occurrence of coccidial infection. The possible reason in which this relation is not established in the present study might be associated with less care given to male calves as compared to the female caves that are dreamed to replace cow [17].

\begin{tabular}{|c|c|c|c|c|c|}
\hline Variable & No examined & No Positives & Prevalence (\%) & $\mathbf{X}^{2}$ & P-value \\
\hline \multicolumn{6}{|c|}{ Sex } \\
\hline Female & 674 & 121 & 55.6 & \multirow{2}{*}{21.148} & \multirow{2}{*}{0.001} \\
\hline Male & 226 & 97 & 44.4 & & \\
\hline \multicolumn{6}{|c|}{ Age } \\
\hline$<6$ & 601 & 183 & 84 & \multirow{2}{*}{17.889} & \multirow{2}{*}{0.001} \\
\hline $6-12$ & 299 & 35 & 16 & & \\
\hline \multicolumn{6}{|c|}{ Breed } \\
\hline Cross & 773 & 204 & 93.8 & \multirow{2}{*}{5.18} & \multirow{2}{*}{0.019} \\
\hline Local & 127 & 14 & 6.2 & & \\
\hline \multicolumn{6}{|c|}{ Production system } \\
\hline Extensive & 186 & 33 & 14.8 & \multirow{2}{*}{2.228} & \multirow{2}{*}{0.136} \\
\hline Intensive & 714 & 185 & 85.2 & & \\
\hline \multicolumn{6}{|c|}{ Hygiene of house } \\
\hline Good & 275 & 43 & 19.8 & \multirow{3}{*}{6.154} & \multirow{3}{*}{0.045} \\
\hline Moderate & 436 & 118 & 54.3 & & \\
\hline $\mathrm{Bad}$ & 189 & 57 & 25.9 & & \\
\hline
\end{tabular}

Table 7: Logistic regression analysis of the prevalence of calf coccidiosis against the associated variable.

\begin{tabular}{|c|c|c|c|c|c|}
\hline Variable & Less infected (\%) & Moderately infected (\%) & Severely infected (\%) & $\mathbf{X}^{2}$ & P-value \\
\hline \multicolumn{6}{|c|}{ Fecal consistency } \\
\hline Diarrheic & 36.4 & 61.9 & 75 & \multirow{3}{*}{85.6} & \multirow{3}{*}{0.00} \\
\hline Soft & 18.2 & 19.0 & 9.4 & & \\
\hline Normal & 45.5 & 19.0 & 15.6 & & \\
\hline \multicolumn{6}{|c|}{ Body condition } \\
\hline Good & 9.1 & 31.3 & 9.4 & \multirow{3}{*}{23.259} & \multirow{3}{*}{0.001} \\
\hline Medium & 45.5 & 40.2 & 40.6 & & \\
\hline Poor & 45.5 & 28.6 & 50.0 & & \\
\hline \multicolumn{6}{|c|}{ Age } \\
\hline$<6$ & 77.3 & 85.7 & 87.5 & \multirow{2}{*}{16.918} & \multirow{2}{*}{0.01} \\
\hline $6-12$ & 22.7 & 14.3 & 12.5 & & \\
\hline
\end{tabular}

Table 8: Intensity of infection in relation to risk factors. 
The study revealed that age of the calves was significantly associated $(\mathrm{P}<0.05)$ with the risk of infection. The highest prevalence was recorded in younger age categories $(<6$ months). This finding agrees with the report of Ref. [17] but in contrast of Ref. [8] who reported that risk of infection by Eimeria species appeared to increase with the age of the examined calves. However, it has been stated that coccidiosis is commonly a disease of young cattle 1-2 months to 1 year [6]. Thus, stress factors like weaning, change of diet, sanitation and overcrowding can increase level of infection [11]. And also previous exposure might have a contribution to the development of certain level immunity of older calves as compared to younger that did not experienced previous exposure $[18,19]$ resulting in more susceptibility to coccidiosis than older calves with immunity from previous exposure.

Statistical significant difference in the prevalence of Coccidiosis between local $(10.6 \%)$ and cross breeds $(26.5 \%)(\mathrm{p}<0.05)$ was disagrees with Ref. [16] who indicated that there was no statistical significant association between breed and coccidia infection. This difference could be, since the local animal sampled was from the extensive production system they can recover early, they produce self-immunity than the cross ones [20,21].

There was no significant difference $(p>0.05)$ in the prevalence of coccidiosis and production system. This result agrees with the report by Ref. [16]. However, as the result shows it's more prevalent in intensive production system (26\%) than the extensive ones (17.4\%); this was justified by Ref. [6] that Coccidiosis in cattle is particularly a problem of confined animals kept under intensive husbandry practices [22].

The highly statistically significant difference $(\mathrm{p}<0.05)$ in the prevalence of Coccidiosis between diarrheic calves (61.5\%) and calves that defecate semisolid feces (15.8\%) and dry feces (9.8\%) was agrees with Ref. [13]. As Ref. [4] was stated on the literature coccidia is the common health problem for both dairy and beef calves by causing acute diarrhea accounts for approximately $75 \%$ of mortality.

Statistically significant difference $(p<0.05)$ has been observed in the occurrence of coccidiosis in the different hygienic status of farms indicating that, calves belonging to the farms with poor hygiene showed higher prevalence than calves belonging to the farms with relatively better hygiene. This could imply that poor sanitation in the calving and calf housing areas as well as poor management of housing favors infection with coccidiosis. Obviously, poor ventilation, draughts, poor calf nutrition, group pens, heavy stocking, cows present with calves, soiled bedding were regarded as risk factors for Coccidiosis $[6,23,24]$.

According to quantities of faecal examination by using Mc master technique, to determine the number of Eimeria oocysts per gram of faeces (OPG) reveled minimum and maximum OPG value of 100 and 3750, respectively. This finding was in line with Ref. [6] reported the minimum value of 100 and max value of 2400 . The result is in the middle when compared with those reported from different countries [8] mean value of 5109 and maximum 267000 Oocyst excretion levels OPG in Addis Ababa and Debre Zeit, Munyua and Ngotho reported a maximum of 30,600 OPG in Kenya [25]. The maximum OPG belong to calf with less than 6 month age category and diarrheic fecal consistency.

\section{Conclusion and Recommendations}

The present study revealed that calf Coccidiosis is prevalent in study area. Sex, fecal consistency, hygiene of the farm and younger age group of calves were strongly associated with the infection of Coccidiosis. According to the results of the present study maximum infection rate was observed in calves less than 6 months of age category. This work strengthens the importance of Eimeria infections in calves in the study area and the infection occurs in almost all areas where cattle are raised and is usually most common and important in calves younger than 1 year. Based on these findings the following recommendations are forwarded:

- The general health status of the calves could be maintained by allowing the calves to obtain sufficient amount of colostrum's within the first 24 hours after birth.

- At farm level, farm workers should give care to minimize any possibility of fecal contamination of the farm and the calves at individual level.

- Giving health care for the calves starting from the isolating them, providing sufficient feed and water.

- Constructing feed and water troughs for individual calve high enough to avoid from any possible feed contamination.

- As early as 15 days of life, the use of prophylactic doses of coccidiostats in ration is advisable to prevent calves from Eimeria infections.

\section{References}

1. Tegegne A, Crawford TW (2000) Draft animal power use in Ethiopia. Draft Animal News 33

2. Central Statistical Agency (2013) Central Statistical Authority Federal Democratic Republic of Ethiopia Agricultural Sample Enumeration Statistical Abstract.

3. Debela $E$ (2002) Epidemiology of gastrointestinal helminthiasis of Rift valley goats under traditional husbandry system in Adami Tulu District, Ethiopia. SINET: Ethiop J Sci 25: 35-44.

4. Heinrichs AJ, Radostits OM (2001) Health and production management of dairy calves and replacement heifers. Herd health, food animal production medicine, pp: 333-395.

5. Urquhart G, Armour J, Dunca J, Dunn A, Jennings F (1996) Veterinary Parasitology. 2nd edn. Blackwell Science Ltd, Oxford, UK, pp: 224-234.

6. Radostitis O, Blood D, Gay C (1994) Veterinary Medicine. 8th edn. Bailliere Tindall, London, pp: 1201-1203.

7. Pilarczyk B, Balicka-Ramisz A (2004) Occurrrence of protozoa Eimeria and Cryptosporidium in calves from west pomerania. Acta Sci Pol Zootechnica 3: 49-56

8. Abebe R, Wossene A, Kumsa B (2008) Epidemiology of Eimeria Infections in Calves in Addis Ababa and Debre Zeit Dairy farms, Ethiopia. Intern J Appl Res Vet Med 6: 24-30.

9. Thrusfield M (2007) Veterinary Epidemiology. 3rd edn. Blackwell Science Ltd. Oxford, UK, pp: 233-261.

10. Hendrix C (1998) Diagnostic veterinary parasitology. 2nd edn. Mosby Inc. USA, pp: 108-116, 136

11. Johannes K (1996) Parasitic infections of domestic animals. A Diagnostic Manual, pp: 24-27.

12. Kassa B, Delgado A, Asegedech T (1985) An outbreak of coccidiosis in cattle. Ethiop Vet Bull 3: 20-27.

13. Yadeessa TK, Awash HD, Gurmu GK (2014) Prevalence of calves coccidiosis in Jimma town dairy farms, South-Western Ethiopia. Scientific Journal of Zoology 3: 36-44.

14. Troncy PM (1989) Helminths of livestock and poultry in tropical Africa. Manual of Trop Vet Parasitol, pp: 1-175

15. Heidari H, Sadeghi-Dehkordi Z, Moayedi R, Gharekhani J (2014) Occurrence and diversity of Eimeria species in cattle in Hamedan province, Iran. Vet Med 59: $271-275$

16. Alemayehu A, Nuru M, Belina T, Mekibib B, Desta T, et al. (2013) Prevalence of bovine coccidia in Kombolcha district of South Wollo, Ethiopia. J Vet Med Anim Health 5: 41-45. 
Citation: Temesgen GK (2016) Epidemiological Studies on Calve Coccidiosis in Dairy Farms in South Wollo Zone Amhara Region, Ethiopia. J Vet Sci Technol 7: 392. doi: 10.4172/2157-7579.1000392

Page 5 of 5

17. Dawid F, Amede Y, Bekele M (2012) Calf coccidiosis in selected dairy farms of dire Dawa, Eastern Ethiopia. Glob Vet 9: 460-464.

18. Chibunda RT, Muhairwa AP, Kambarage DM, Mtambo MMA, Kusiluka LJM, et al. (1997) Eimeriosis in dairy cattle farms in Morogoro municipality of Tanzania. Prev Vet Med 31: 191-197.

19. Faber JE, Kollmann D, Heise A, Bauer C, Failing K, et al. (2002) Eimeria infections in cows in the periparturient phase and their calves: oocyst excretion and levels of specific serum and colostrum antibodies. Vet Parasitol 104: 1-17.

20. Ahmed WM, Hassan SE (2007) Applied studies on coccidiosis in growing Buffalo-calves with special reference to oxidant/antioxidant status. World $\mathrm{J}$ Zool 2: 40-48.
21. Agricultural Sample Survey (2013) Report on livestock and livestock characteristics.

22. Gooch CA, Inglis SF, Czymmek KJ (2005) Mechanical solid-liquid manure separation: performance evaluation on four New York State dairy farms-A preliminary report. In: 2005 ASAE Annual Meeting. American Society of Agricultural and Biological Engineers.

23. Daugschies A, Najdrowski M (2005) Eimeriosis in cattle: current understanding J Vet Med Series B 52: 417-427.

24. International Dairy Federation and Food and Agriculture Organization (2011) Publish revised guide to sustainable dairy farming practices.

25. Nicholson MJ, Butterworth MH (1986) A guide to condition scoring of zebu cattle. ILRI (aka ILCA and ILRAD). 